\title{
Influence of soil particle shape on saturated hydraulic conductivity
}

\author{
Zofia Zięba
}

Institute of Building Engineering, Wrocław University of Environmental and Life Sciences, 24 Grunwaldzki Sq., 50-363 Wrocław, Poland. Tel.: +48 7132055 43. Fax: +48 7132055 84. E-mail: zofia.zieba@up.wroc.pl

\begin{abstract}
The aim of this paper is to define the correlation between the geometry of grains and saturated hydraulic conductivity of soils. The particle shape characteristics were described by the $\zeta_{O C}$ index (Parylak, 2000), which expresses the variability of several shape properties, such as sphericity, angularity and roughness.

The analysis was performed on samples of four soils, which were characterised by the same grain size distribution and extremely different particle structure. The shape characteristics varied from ideally spherical, smooth grains (glass microbeads GM) to highly irregular and rough particles (fly ash FA).

For each soil, laboratory tests of saturated hydraulic conductivity (constant head test CHT and falling head test FHT) were performed. Additionally, an empirical analysis of effective pore diameter was conducted with use of the analytical models developed by Pavchich (Wolski, 1987) and Indraratna and Vafai (1997). The models were modified by introducing the $\zeta_{0 C}$ index.

Experiments have shown that saturated hydraulic conductivity depends on grains shape and surface roughness. This parameter decreases with the increase in the irregularity of soil particles. Moreover, it was proven that the $\zeta_{O C}$ reflects the relationship between effective pore diameter and grain shape characteristics.
\end{abstract}

Keywords: Particle shape; Saturated hydraulic conductivity; Effective pore diameter.

\section{INTRODUCTION}

In order to precisely define soil properties, a detailed recognition of the mechanisms and phenomena that influence such properties is required. Amongst the factors determining soil behaviour are grain size distribution, mineral composition, as well as the particle shape and roughness.

The particle shape has a particularly significant influence on soil properties. Numerous researchers concluded that the shape of particles is the decisive factor that determines soil behaviour (Masad, 2005; Pena et al., 2007; Santamarina and Cho, 2004).

However, literature does not provide an explicit, exhaustive description of the issues related to the definition of particle shape properties and the methods of the determination thereof (Cox and Badhu, 2008).

The year 1932, when Wedell published his pioneering works (Wadell, 1932), is considered the beginning of studies on grain shape characteristics. Since that time, numerous methods of particle shape analysis have been developed. The simplest techniques consist of the visual evaluation of shape (Harr, 1977; Lambe and Whitman, 1979; Yagiz, 2001). Other methods express the proportions of the geometrical sizes of particles obtained through direct measurement (Domokos et al., 2011) or through the measurement of images obtained with use of advanced equipment. This device may be the light microscope (Gori and Mari, 2001; Vallejo, 1995), scanning electron microscope SEM (Cox and Badhu, 2008; Thomas et al., 1995), computed tomography X-ray (Cox and Badhu, 2008; Masad, 2005) or 3D laser (Garboczi et al., 2006; Sinecen et al., 2011). More complex approaches to shape analysis include calculation methods, such as Fourier analysis (Bowman et al. 2001; Thomas et al., 1995), the fractal method (Arasan et al., 2011; Gori and Mari, 2001; Vallejo, 1995) and the use of neural networks (Sinecen et al., 2011).

Unfortunately, regardless of the continuous development of techniques and equipment, the main problem with the quantitative approach to particle shape analysis is the difficulty in defining their variability (Cox and Badhu, 2008). Furthermore, most of these methods do not describe the variability of several particle shape properties with use of a single parameter, although the need for such a solution was indicated as early as the 1970s (Frosard, 1979).

One of the exceptions was the study by Parylak (2000), who introduced the total shape index $\zeta_{O C}$ that describes the sphericity, angularity and roughness of the grains. The determined parameter was the basis for further analyses of the influence of particle shape on the values of the internal friction angle (Mamok, 2004) and on soil compressibility parameters (Chmielewski, 2006). Significant impact of the geometrical properties of particles, expressed by the $\zeta_{O C}$ index, on the formation of shear strength and compressibility parameters was proven in these works. Therefore, it became interesting to recognise the influence of the $\zeta_{O C}$ index on the remaining soil properties, including hydraulic conductivity, which is the key parameter describing the water movement through the soil profile (Hillel, 2004; Klipa et al., 2015).

The particle shape determines the size and geometry of the pore space, which is decisive for the water flow, as well as the capability to retain bound water (Parylak and Zięba, 2012). The surface shape and roughness of the particles contribute to the reduction of pore space where free-water flow may occur. Thus, particle shape characteristics determine the effective porosity that is decisive for the soil hydraulic conductivity (Aimrun et al., 2004; Brooks and Corey, 1964; Hillel, 2004; Jetel, 1975; Valentin et al., 2016).

The correlation between soil hydraulic conductivity and the characteristics of the pore space has been the subject of numerous studies. However, most of analyses focused only on the determination of the influence of the pore size distribution, while omitting properties such as the shape and configuration of particle surface (Cuisinier et al., 2011; Garcia-Bengochea, 1978; Sasal et al., 2006; Tran et al., 2014; White and Williams, 1999). Some empirical equations, such as the Kozeny-Carman formula or its simplified form proposed in the Taylor formula, are an attempt to describe the shape and curvature of pores (Carrier, 2003; Lambe and Whitman, 1979). However, these 
equations do not present a method that would enable the precise definition of shape characteristics and the determination of its influence on water movement. More recent research has also demonstrated that the application of empirical equations to determine the hydraulic conductivity of soil is not reliable, mainly due to the omission or insufficient consideration of the influence of their shape properties (Parylak et al., 2013).

The aim of this study is to determine the correlation between the particle shape characteristics defined by the total shape index $\zeta_{O C}$ and saturated hydraulic conductivity $K$. Literature does not provide a comprehensive method that would enable the description of $K$ with reference to shape properties.

\section{MATERIALS}

The hydraulic conductivity of the soil is determined mainly by its properties. The most important of these characteristics include grain size distribution, porosity, mineral composition, degree of saturation, as well as the shape and roughness of particles (Cadergen, 1997; Head and Epps, 2011).

In this study, four soil materials characterised by a gradual variability of particle shape properties were selected. Geometrical characteristics varied from perfectly smooth and round grains to highly irregular particles with a rough surface. The selected soils were characterised by the same grain size distribution, as well as a similar mineral composition. This enabled the elimination of factors other than particle shape that might influence the values of saturated hydraulic conductivity.

As in the previous experiments (Chmielewski, 2006; Mamok, 2004; Parylak, 2000), the following materials were selected for the tests: artificial glass microbeads - GM, eolian soil from Krakowiany - SK, waste silt from the granite processing plant in Graniczna - SG and fly ash from hard coal - FA (Fig. 1).

\section{METHODS}

The basic properties of the analysed soils that influence saturated hydraulic conductivity, such as grain size distribution, specific surface area $S$ and porosity $n$, were determined according to the Eurocode 7 standard (EN 1997-2, 2007).

\section{Particle shape characteristics}

The particle shape was defined with use of the total shape index $\zeta_{O C}$, which takes into account sphericity, angularity and roughness (Parylak, 2000).

The sphericity $\Phi$ was calculated based on Equation 1, as the surface area of a sphere of the same volume as the particle $\left(A_{S}\right)$ divided by the surface area of the particle $\left(A_{P}\right)$ (Lees, 1964) (Fig.2a).

$$
\Phi=\frac{A_{S}}{A_{P}}
$$

The angularity $A$ was quantified based on Equation 2 (Lees, 1964).

$$
A=\sum\left[\left(180-\beta_{i}\right) \cdot \frac{x_{i}}{r}\right]
$$

where: $\beta_{i}-$ angle bounding the particle edge, $x_{i}$ - distance from center of the maximum inscribed circle to the particle edges, $r$ - radius of the maximum inscribed circle, assumed to be the center of the particle (Fig. 2b).

The surface roughness $I_{a}$ was calculated with use of Equation 3 (Parylak, 2000).

$$
I_{a}=\frac{P_{R}-P_{S}}{P_{S}}
$$

where: $P_{R}-$ actual perimeter of the particle, $P_{S}-$ simplified perimeter of the particle (Fig. 2c).
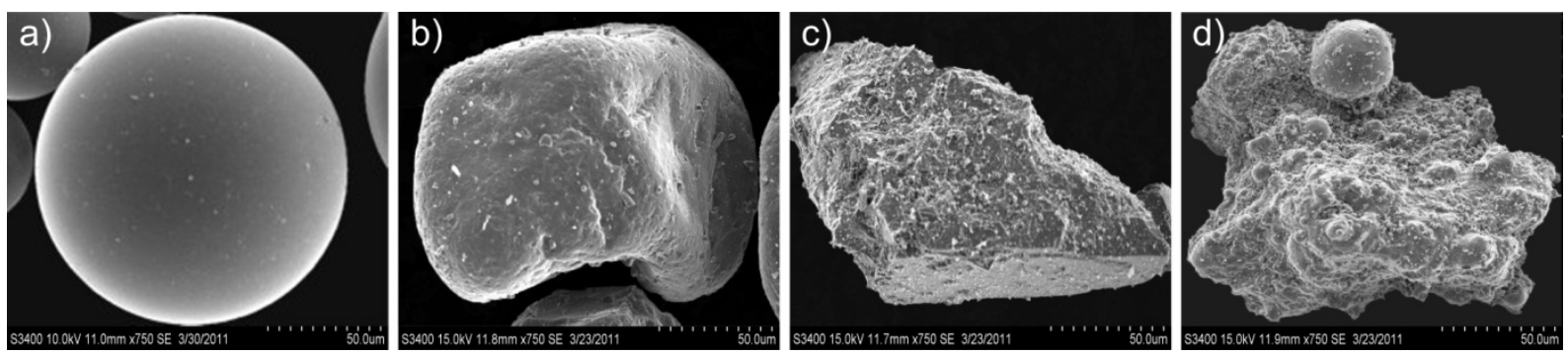

Fig. 1. Scanning Electron Microscope SEM images of soils particles: a) GM; b) SK; c) SG; d) FA.
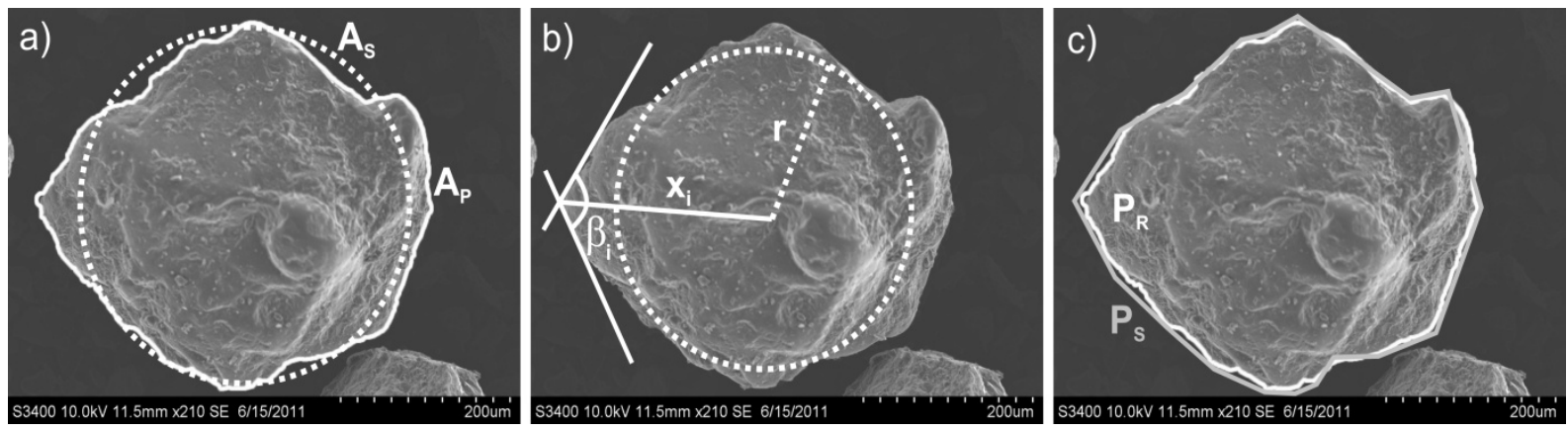

Fig. 2. Determination of the shape characteristics: a) sphericity; b) angularity; c) roughness. 
In order to determine the simplified perimeter, a polygon was drawn in such a way that the edges of each larger shape irregularity were replaced with a section of a straight line. The method is based on the fundamental assumption that the area of the polygon of the simplified perimeter must be equal to the actual area of the analysed cross-section.

For each of the properties, the shape index $\zeta_{0}\left(\zeta_{\Phi}, \zeta_{1-A}, \zeta_{1-I a}\right)$ was determined (Equation 4) that included their minimum $\left(\zeta_{\min }\right)$, average $\left(\zeta_{a v}\right)$ and maximum $\left(\zeta_{\max }\right)$ values.

$\zeta_{0}=\frac{\zeta_{a v}-\zeta_{\min }}{\zeta_{\max }-\zeta_{\min }}$

Then, the total shape index $\zeta_{O C}$ was calculated (Equation 5).

$\zeta_{0 C}=\frac{\zeta_{\Phi}+\zeta_{1-A}+\zeta_{1-I a}}{3}$

This parameter was determined based on SEM images analysis. Photographs were taken of soil samples in loose state. Soil grains were placed on adhesive carbon rings and covered with conductive layer. Images were taken with use of scanning electron microscope HITACHI S-3400N. Thirty SEM images of each soil were analysed. The geometrical properties of specific particles required for the determination of their shape characteristics were identified automatically, with use of ImageJ software (Rasband, 1997-2016).

The obtained shape property values were then subject to statistical analysis. The arithmetic mean and standard deviation were calculated for the significance level equal to $0.05(-)$. Next, the dispersion of results with respect to mean value was determined by calculating the coefficient of variation. If its value does not exceed $10 \%$, then it is assumed that the variability of the given property is statistically insignificant. Otherwise, the extreme values should be rejected (Sheskin, 2003). The analysis was conducted with use of Statistica software.

\section{Hydraulic conductivity}

Due to the grain size distribution of materials from the borderline area of cohesive and non-cohesive soils, two test methods were used: the constant head test CHT, which is a typical test of non-cohesive soils and the falling head test FHT, which is applied to cohesive soils (Dawson, 2008; Head and Epps, 2011).

The CHT was performed on samples of a diameter of $80 \mathrm{~mm}$ and a height of $30 \mathrm{~mm}$, while the FHT on samples of a diameter of $75 \mathrm{~mm}$ and $20 \mathrm{~mm}$ height. The sample sizes were dictated by the construction of the apparatuses used. The samples were protected from particle movement by the placement of filters on the top and bottom sides. Ceramic porous stones of a saturated hydraulic conductivity equal to $10^{-4}\left(\mathrm{~m} \mathrm{~s}^{-1}\right)$ were used.

In both cases tests were conducted on samples of the same density index $I_{D}$ in four variants $\left(I_{D}=0.1 ; 0.3 ; 0.6 ; 0.9\right)$. Samples were compacted directly in the cylinders of the apparatus. At the stage of compaction, the soils were in an air-dry state. For each density variant the saturated hydraulic conductivity was measured for three different hydraulic gradients $(i=0.3$; $0.5 ; 0.8)$.

In order to avoid air entrapment in the samples the tests were conducted with the use of de-aired, distilled water. Measurements were preceded by slow saturation. Changes in sample height were measured during the tests to control compaction.

In order to compare the results of CHT and FHT for the given density indexes, the statistical analysis of correlation was conducted using Statistica software. For the significance level equal to $0.05(-)$, the Pearson correlation coefficient $r$ was calculated for each type of soil (Sheskin, 2003). The results were presented on scatter plots.

\section{Empirical analysis of effective pore diameter with reference to particle shape characteristics}

In order to describe the relationships between the geometry and roughness of particle surface and the saturated hydraulic conductivity, an empirical analysis of the effective porosity expressed by effective pore diameter was conducted, based on simple analytical models. In the previous study (Parylak and Zięba, 2012), based on the Pavchich model (Wolski, 1987) (Equation 6), calculations were conducted for two types of soils characterised by extremely different shape properties, i.e. for GM and FA. For the purposes of the present study, this model was applied to all types of the analysed soils.

$D_{p}=0.455 \cdot \sqrt[6]{C_{u}} \cdot \frac{n}{1-n} \cdot D_{17}$

where: $D_{p}$ - effective pore diameter, $n$ - porosity, $C_{u}$ - uniformity coefficient, $D_{17}-$ the size such that $17 \%$ of the particles are smaller than $D_{17}$

Additionally, the Indraratna and Vafai model (1997) (Equation 7) was used, as it is the only model which includes particle shape.

$$
D_{i v}=2.67 \cdot \frac{n}{1-n} \cdot \frac{D_{h}}{\alpha}
$$

where: $D_{i v}$ - effective pore diameter, $n$ - porosity, $\alpha-$ shape factor, $D_{h}$ - mass weighted diameter.

In both cases two variants of the analysis were conducted. In the first one, the effective pore diameters $D_{p}$ and $D_{i v}$ were calculated with use of the selected models. In the second variant the $\zeta_{0 C}$ index was introduced to both models as a parameter adjusting the value of general porosity (Equations 8,9).

$$
\begin{aligned}
& D_{p}{ }^{*}=0.455 \cdot \sqrt[6]{C_{u}} \cdot \frac{n \cdot \zeta_{0 C}}{1-n \cdot \zeta_{0 C}} \cdot D_{17} \\
& D_{i v}{ }^{*}=2.67 \cdot \frac{n \cdot \zeta_{0 C}}{1-n \cdot \zeta_{0 C}} \cdot \frac{D_{h}}{\frac{1}{\zeta_{0 C}}}
\end{aligned}
$$

In the Indraratna and Vafai model the shape index $\alpha$ was replaced by the $\zeta_{O C}$ index, because $\alpha$ only describes angularity. Moreover, the shape is determined by assigning the shape of the analysed particles to one of five groups (Sphere, Cube, Tetrahedron, Kaolinite, Na-Montmorillonite) pursuant to subjective visual assessment (Indraratna et al., 1996).

Due to the fact that the values of the $\alpha$ increase, but the values of the $\zeta_{O C}$ decrease with the increase in shape irregularity, the reciprocal of $\zeta_{0 C}$ was used in equation 9. 


\section{RESULTS AND DISCUSSION}

The results have shown an insignificant differentiation of grain size distribution (Fig. 3) and its properties, such as the uniformity coefficient $C_{u}$ and the grain curvature coefficient $C_{c}$ (Table 1). Such selection of the analysed material allowed for the elimination of grain size distribution as a factor influencing the saturated hydraulic conductivity of the analysed soil materials.

The tests have also shown a high differentiation in the values of the specific surface area $S$. This parameter reflects the roughness of the external particle surface and determines the capability of soil to retain bound waters on its surface, as it determines the strength of superficial forces (Utkaeva, 2007) (Table 1).

\section{Particle shape characteristics}

The obtained total shape index values showed a tendency to decrease with the increase in the complexity of the geometry and configuration of particle surface (Parylak, 2000) (Table 2).

Discrepancies were also noted for the porosity values. This variability results mainly from the different edge sharpness and shape irregularity of the particles of specific soil types (Nimmo, 2005). The more irregular and the rougher they are, the higher the porosity (Table 3 ).

\section{Hydraulic conductivity}

The statistical analysis of the results based on CHT and FCT has shown a very strong positive correlation between those two methods (Fig. 4). The Pearson correlation coefficient $r$ remains close to 1 in all cases (Sheskin, 2003).

Considering the lack of statistically significant differences, the obtained values of hydraulic conductivity were averaged and are listed in Table 3.

Assuming that the obtained results were credible, an analysis of the correlation between the saturated hydraulic conductivity and the total shape index at various density indexes was conducted.

The Fig. 5 suggests that the value of the saturated hydraulic conductivity decreases along with the increase in shape irregularity and roughness of the soil particles. This is opposite to the

Table 1. Parameters of the analysed soils.

\begin{tabular}{lccc}
\hline Soil type & $\begin{array}{c}\text { Uniformity } \\
\text { coefficient } \\
C_{u}\end{array}$ & $\begin{array}{c}\text { Curvature } \\
\text { coeffcient } \\
C_{c}\end{array}$ & $\begin{array}{c}\text { Specific surface } \\
\text { area } \\
S\end{array}$ \\
\hline$(-)$ & $(-)$ & $(-)$ & $\left(\mathrm{m}^{2} \cdot \mathrm{g}^{-1}\right)$ \\
\hline GM & 3.40 & 0.78 & 0.27 \\
SK & 3.80 & 0.69 & 0.40 \\
SG & 3.80 & 0.69 & 0.45 \\
FA & 3.20 & 0.67 & 1.34 \\
\hline
\end{tabular}

Table 2. Particle shape characteristics.

\begin{tabular}{lcccc}
\hline $\begin{array}{l}\text { Soil } \\
\text { type }\end{array}$ & $\begin{array}{c}\text { Sphericity } \\
\text { index } \zeta_{\Phi}\end{array}$ & $\begin{array}{c}\text { Angularity } \\
\text { index } \zeta_{(-A)}\end{array}$ & $\begin{array}{c}\text { Roughness } \\
\text { index } \zeta_{(-I a)}\end{array}$ & $\begin{array}{c}\text { Total shape } \\
\text { index } \zeta_{0 C}\end{array}$ \\
\hline$(-)$ & $(-)$ & $(-)$ & $(-)$ & $(-)$ \\
\hline GM & 1.00 & 1.00 & 1.00 & 1.00 \\
SK & 0.45 & 0.66 & 0.89 & 0.67 \\
SG & 0.26 & 0.57 & 0.90 & 0.58 \\
FA & 0.27 & 0.38 & 0.78 & 0.48 \\
\hline
\end{tabular}

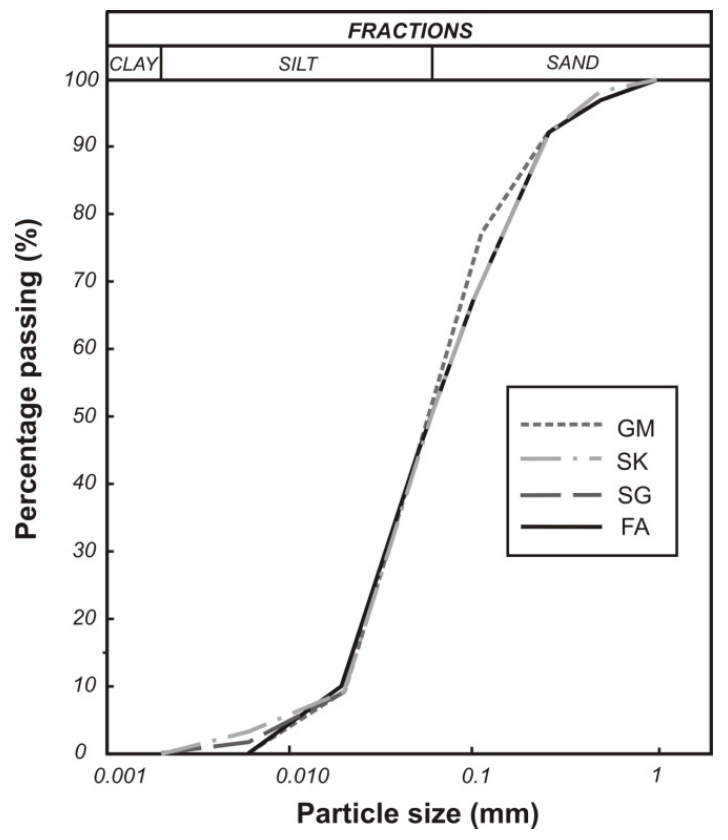

Fig. 3. Grain size distribution of analysed soils.

trend that saturated hydraulic conductivity show in relation to porosity results (Table 3 ). The highest porosity values were found in FA, which is also characterised by the lowest hydraulic conductivity.

The tests were conducted on soils characterised by similar grain size distribution and mineral composition in the same sample compaction conditions. The existing differences in the values of hydraulic conductivity may result only from the differences in particle shape properties.

Literature does not provide a strictly defined direct relation between porosity and water permeability. However, it is often assumed that an increase in porosity leads to increased hydraulic conductivity (Tiab and Donaldson, 2016). The conducted tests prove the opposite.

Table 3. Saturated hydraulic conductivity $K$ in relation to the density.

\begin{tabular}{lccc}
\hline Soil type & $\begin{array}{c}\text { Density } \\
\text { index } \\
I_{D}\end{array}$ & $\begin{array}{c}\text { Porosity } \\
n\end{array}$ & $\begin{array}{c}\text { Saturated hydraulic conductivity } \\
K\end{array}$ \\
\hline$(-)$ & $(-)$ & $(-)$ & $\left(\mathrm{m} \cdot \mathrm{s}^{-1}\right)$ \\
\hline \multirow{4}{*}{$\mathrm{GM}$} & 0.10 & 0.38 & $1.58 \cdot 10^{-5}$ \\
& 0.30 & 0.36 & $1.39 \cdot 10^{-5}$ \\
& 0.60 & 0.32 & $1.18 \cdot 10^{-5}$ \\
& 0.90 & 0.27 & $9.96 \cdot 10^{-6}$ \\
\hline \multirow{3}{*}{$\mathrm{SK}$} & 0.10 & 0.47 & $8.94 \cdot 10^{-6}$ \\
& 0.30 & 0.44 & $7.99 \cdot 10^{-6}$ \\
& 0.60 & 0.40 & $6.45 \cdot 10^{-6}$ \\
& 0.90 & 0.35 & $5.20 \cdot 10^{-6}$ \\
\hline \multirow{3}{*}{$\mathrm{SG}$} & 0.10 & 0.50 & $6.99 \cdot 10^{-6}$ \\
& 0.30 & 0.48 & $6.23 \cdot 10^{-6}$ \\
& 0.60 & 0.44 & $4.53 \cdot 10^{-6}$ \\
& 0.90 & 0.40 & $3.50 \cdot 10^{-6}$ \\
FA & 0.10 & 0.51 & $3.66 \cdot 10^{-6}$ \\
& 0.30 & 0.49 & $3.35 \cdot 10^{-6}$ \\
& 0.60 & 0.45 & $2.53 \cdot 10^{-6}$ \\
\hline
\end{tabular}



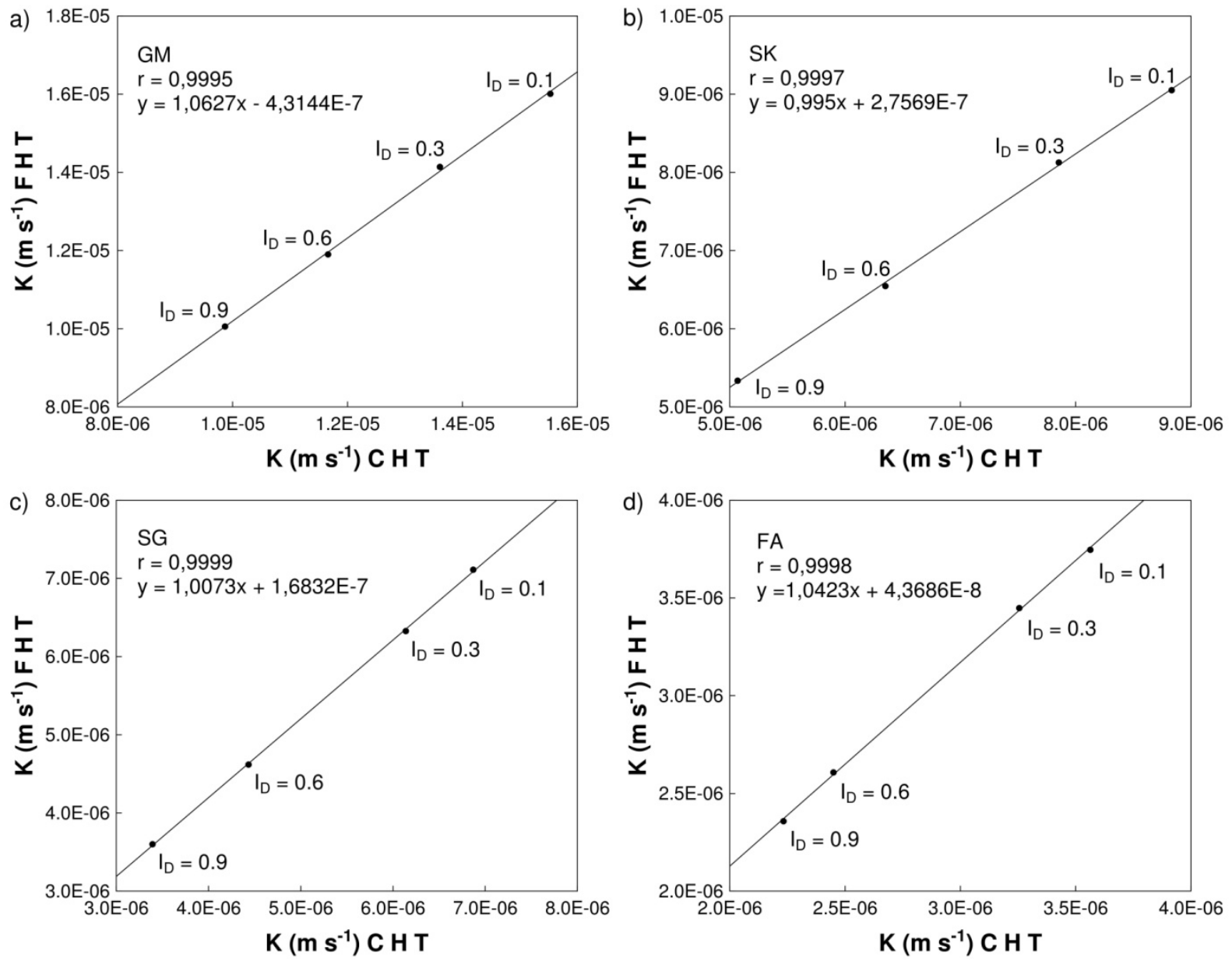

Fig. 4. Correlation between the saturated hydraulic conductivity $K$ based on CHT and FHT: a) GM; b) SK; c) SG; d) FA.

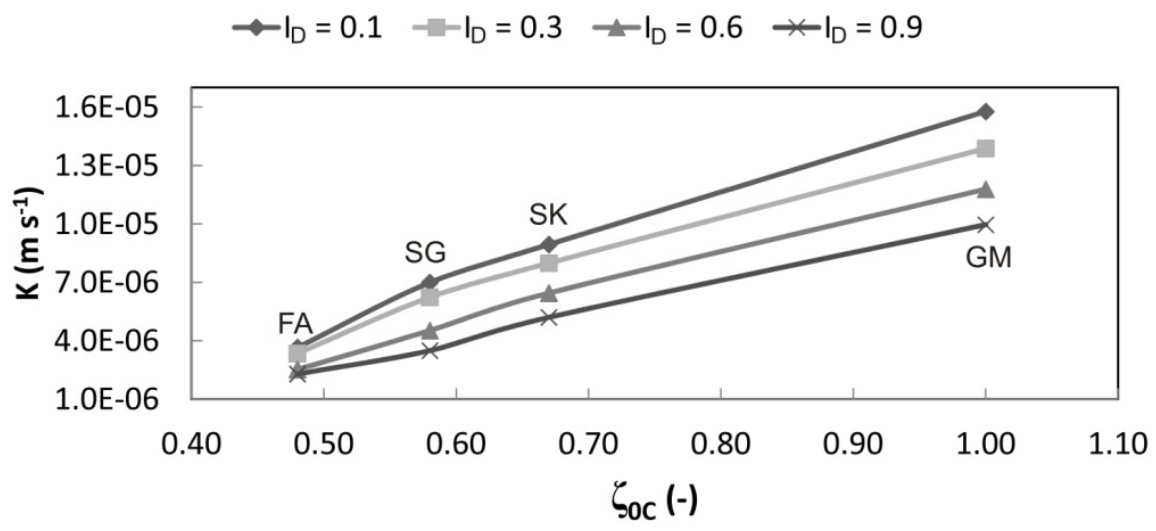

Fig. 5. Correlation between the saturated hydraulic conductivity $K$ and the total shape index $\zeta_{O C}$ at various density indexes $I_{D}$.

\section{Empirical analysis of effective pore diameter with reference to particle shape characteristics}

Effective porosity is considered to be the decisive parameter for the hydraulic conductivity properties of soil (Aimrun et al., 2004; Brooks and Corey, 1964; Hillel, 2004; Jetel, 1975; Valentin et al., 2016). Thus, the dependence of effective pore diameter on the $I_{D}$ should reflect the tendency in saturated hydraulic conductivity changes with respect to density changes.

Diagrams of correlations between effective pore diameter and density index were prepared in order to compare the obtained dependencies. In the first variant, effective pore diameters were calculated based on the original analytical models $\left(D_{p}, D_{i v}\right)$ according to Equations 6 and 7 (Fig. 6a, 6b), while in the second variant, the models were modified $\left(D_{p}{ }^{*}, D_{i v}{ }^{*}\right)$ based on Equations 8, 9 (Fig. 6c, 6d).

Fig. 6a shows that in the case of the original Pavchich model the relationship between the effective pore diameter and the density index reflected the dependence of porosity (Table 3 ) on this parameter. 
a)

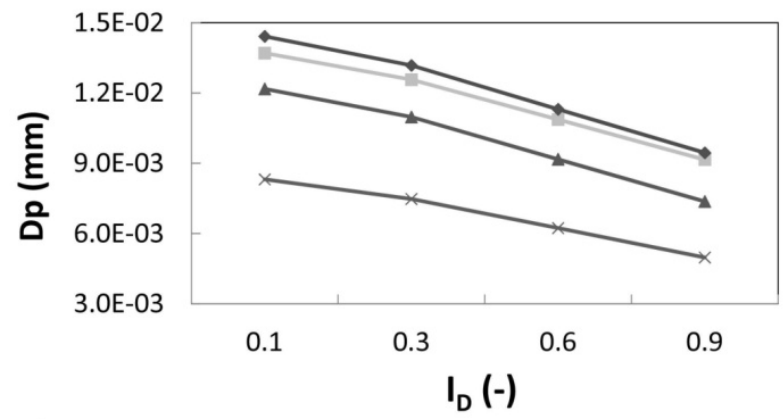

c)

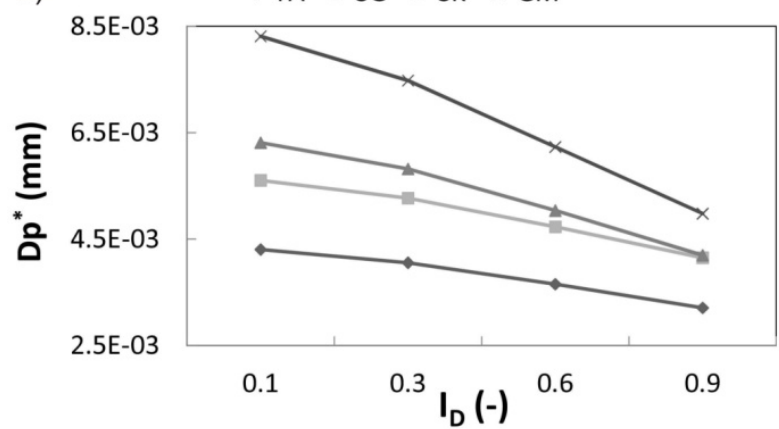

b)

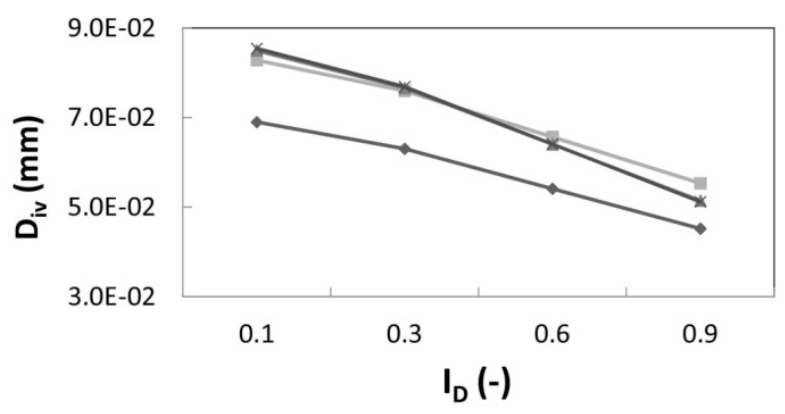

d)

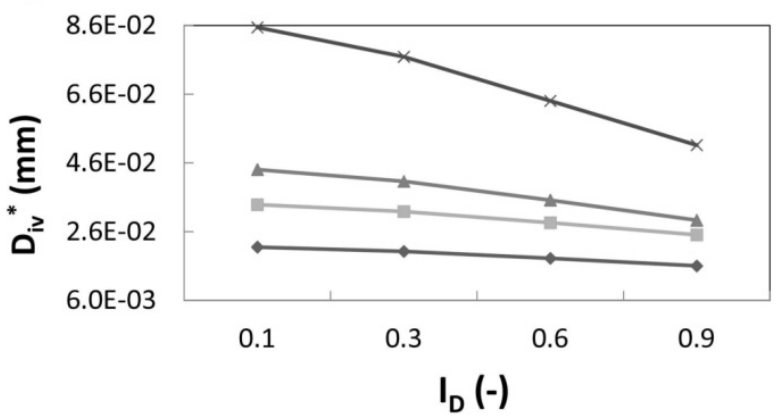

Fig. 6. Dependence of effective pore diameter on density index $I_{D}$ : a) Pavchich model; b) Indraratna and Vafai model; c) modified Pavchich model; d) modified Indraratna and Vafai model.

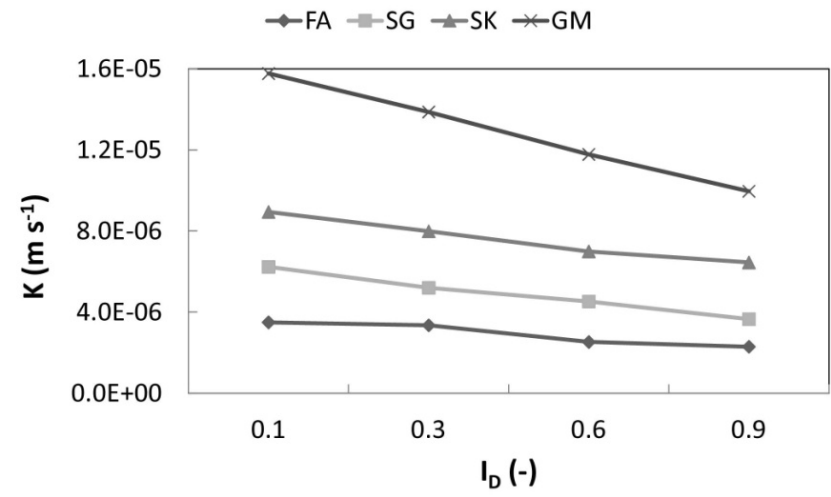

Fig. 7. Correlation between the saturated hydraulic conductivity $K$ obtained in laboratory tests and the density index $I_{D}$.

In the case of the Indraratna and Vafai model, including the $\alpha$ coefficient resulted in the fact that the FA had the lowest values of minimum pore channel diameter. However, for the remaining soils these values were very similar, and in the case of GM and SK they were practically identical (Fig. 6b).

After the introduction of the total shape index to both models as the value adjusting porosity, in both cases the highest effective pore diameter values were obtained for GM, followed by SK, SG, and the lowest for FA (Fig. 6c, 6d).The obtained relationships were verified by comparing them to laboratory test results (Fig. 7). In order to further analyse the obtained similarities, the changes in saturated hydraulic conductivity were compared to the changes in $D_{p}{ }^{*}$ (Fig. 8a) and $D i v^{*}$ (Fig. $8 \mathrm{~b}$ ). The results of the statistical analysis (at the significance level of 0.05 ) have shown a very strong positive correlation (Fig. 8). In all instances, the values of the Pearson correlation coefficient $r$ exceed 0.9 .

The results suggest that the total shape index enables appropriate adjustment of the selected analytical models. Thus, it may be stated that it is a value that numerically reflects the a)

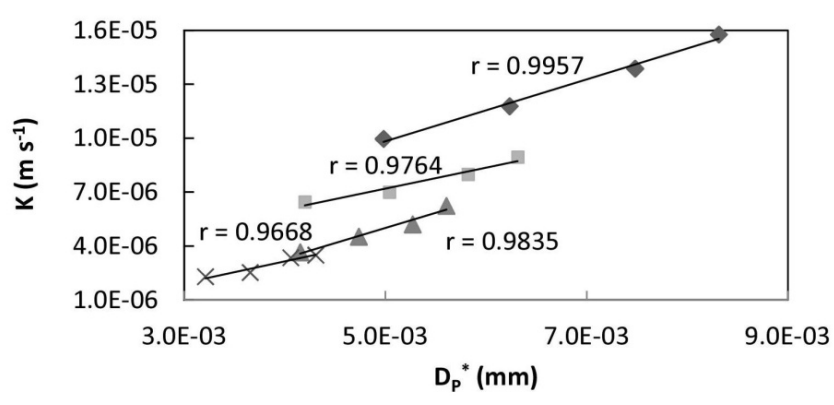

b)

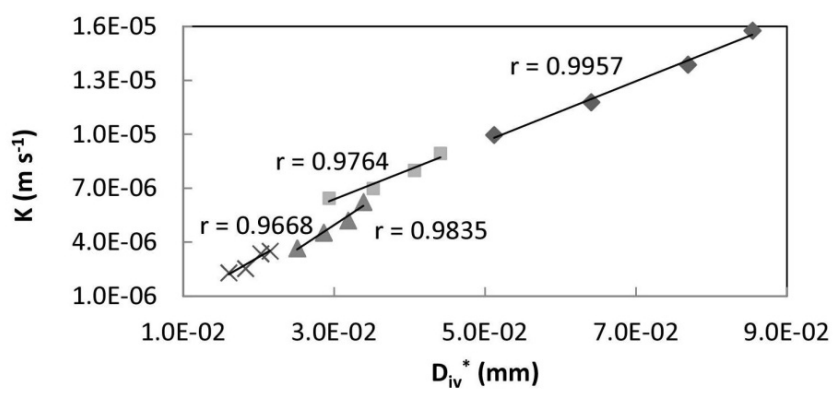

Fig. 8. Correlation between the changes in the saturated hydraulic conductivity $K$ and effective pore diameter caused by the increase in the density index $I_{D}$ : a) modified Pavchich model $D_{p}{ }^{*}$; b) modified Indraradna and Vafai model $D_{i v}{ }^{*}$.

capability of the soil to retain bound water. The lower the value of the $\zeta_{O C}$ index, the higher the amount of bound water and the lower the diameter of pores. The conducted analysis explains why the fly ash, characterised by higher porosity (Table 3), shows lower saturated hydraulic conductivity in comparison to the other soils (Fig. 7). 


\section{CONCLUSIONS}

1. Laboratory tests have shown that saturated hydraulic conductivity is closely related to the shape and roughness of soil particles expressed as the total shape index $\zeta_{O C}$. It was proven that the saturated hydraulic conductivity of soils decreases with the reduction in the $\zeta_{O C}$ index - with the increasing shape irregularity of particles.

2. It was demonstrated that the trend of the relationship between $K$ and $\zeta_{O C}$ index is opposite to the relationship between $K$ and porosity $n$. Porosity values were the highest for soils of the most complex grain structure.

3. The modification of the Pavchich model and the Indraratna and Vafai model by introducing the $\zeta_{0 C}$ index allowed for the expression of effective pore diameter in terms of particle shape characteristics.

\section{REFERENCES}

Aimrun, W., Amin, M.S.M., Eltaib, S.M., 2004. Effective porosity of paddy soils as an estimation of its saturated hydraulic conductivity. Geoderma, 121, 197-203.

Arasan, S., Akbulut, S., Hasiloglu, S. A., 2011. The relationship between the fractal dimension and shape properties of particles. Journal of Civil Engineering, 15, 7, 1219-1225.

Bowman, E.T., Soga, K., Drummond, W., 2001. Particle shape characterisation using Fourier descriptor analysis. Geotechnique, 51, 6, 545-554.

Brooks, R., Corey, A., 1964. Hydraulic properties of porous media. Hydrology Paper, Colorado State University, 3, $1-27$.

Cadergen, R., 1997. Seepage, Drainage and Flow Nets. 3rd ed. John Wiley and Sons, New York, $467 \mathrm{p}$.

Carrier, D., 2003. Goodbye, Hazen; Hello, Kozeny-Carman. Technical notes. Journal of Geotechnical and Geoenvironmental Engineering, 129, 11, 1054-1056.

Chmielewski, M., 2006. Badania nad wpływem cech kształtu cząstek gruntów niespoistych na wybrane parametry ściśliwości. [The influence of particles shape of fine-grained noncohesive soils on the selected parameters of compressibility]. PhD Thesis. Wrocław, 117 p. (In Polish.)

Cox, M., Badhu, M., 2008. A practical approach to grain shape quantification. Engineering Geology, 96, 1-16.

Cuisinier, O., Auriol, J.C., Borgne, T.L., Deneele, D., 2011. Microstructure and hydraulic conductivity of a compacted lime-treated soil. Engineering Geology, 123, 187-193.

Dawson, A., 2008. Water in Road Structures - Movement, Drainage and Effects. Springer, Dordrecht, 436 p.

Domokos, G., Sipos, A., Szabó, T., Várkonyi, P., 2011. Pebbles, shapes and equilibria. Mathematical Geosciences, 42, 29-47.

EN 1997-2, 2007. Eurocode 7 - Geotechnical design - Part 2: Ground investigation and testing.

Frosard, A., 1979. Effect of sand grain shape on interparticle friction, indirect measurements by Rowe's stress dilatancy theory. Geotechnique, 3, 341-350.

Garboczi, E.J., Cheok, G.S., Stone, W.C., 2006. Using LADAR to characterize the 3-D shape of aggregates: Preliminary results. Cement and Concrete Research, 36, 2006, 10721075.

Garcia-Bengochea, I., 1978. The Relation between Permeability and Pore Size Distribution of Compacted Clayey Silts: Interim Report. Joint Transportation Research Program Technical Report Series, Purdue University, West Lafayette, Indiana, $179 \mathrm{p}$.
Gori, U., Mari, M., 2001. The correlation between the fractal dimension and internal friction angle of different granular materials. Soils and Foundations, 41, 6, 17-23.

Harr, E., 1977. Mechanics of Particulate Media - a Probabilistic Approach. McGraw-Hill, New York, 543 p.

Head, K., Epps, R., 2011. Manual of Soil Laboratory Testing, Vol. 2, Permeability, Shear Strength and Compressibility Test. 3rd ed. Whittles Publishing, Dunbeath Mill, 480 p.

Hillel, D., 2004. Introduction to Environmental Soil Physics. 1st ed. Academic Press, San Diego, 494 p.

Indraratna, B., Vafai, F., 1997. Analytical model for particle migration within base soil-filter system. Journal of Geotechnical and Geoenvironmental Engineering, 123, 2, 100-109.

Indraratna, B., Vafai, F., Dilema, E.L.G., 1996. An experimental study of the infiltration of a lateritic clay slurry by sand filters. Proceedings of the Institution of Civil Engineers. Geotechnical Engineering, 119, 2, 75-83.

Jetel, J., 1975. Hydrogeologická interpretace jednotlivých kategorií efektivní pórovitosti. [The hydrogeological interpretations of the effective porosity categories]. Ústřední Ústav Geologický, Praha, 39 p. (In Czech.)

Klípa, V., Sněhota, M., Dohnal, M., 2015. New automatic minidisc infiltrometer: design and testing. Journal of Hydrology and Hydromechanics, 63, 2, 110-116.

Lambe, W., Whitman, R., 1979. Soil Mechanics. John Wiley \& Sons, New York, $553 \mathrm{p}$.

Lees, G., 1964. New method for determining the angularity of particles. Sedimentology, 3, 2-21.

Mamok, B., 2004. Wpływ zagęszczenia i nieregularności kształtu cząstek drobnoziarnistych gruntów niespoistych na wartości kąta tarcia wewnętrznego. [The influence of density and particles shape irregularities of fine-grained noncohesive soils on the internal friction angle]. $\mathrm{PhD}$ Thesis, Wrocław, 87 p. (In Polish.)

Masad, E., 2005. Computations of particle surface characteristics using optical and X-ray CT image. Computational Material Science, 34, 406-424.

Nimmo, J.R., 2005. Porosity and Pore Size Distribution. In: Hillel, D. (Ed.): Encyclopedia of Soils in the Environment, Vol. 3. Elsevier, London, pp. 295-303.

Parylak, K., 2000. Charakterystyka kształtu cząstek drobnoziarnistych gruntów niespoistych i jej znaczenie w ocenie wytrzymałości. [Characteristic of particles shape of finegrained cohesionless soils and its significance in strength assessment]. Zeszyty Naukowe Politechniki Śląskiej, no 90, Gliwice, 130 p. (In Polish with English abstract.)

Parylak, K., Zięba, Z., 2012. Metoda określania parametrów przestrzeni porowej gruntów niespoistych $\mathrm{z}$ uwzględnieniem kształtu cząstek. [The method for determining the pore space parameters of non-cohesive soils including particles shape]. Inżynieria Morska i Geotechnika, 4/2012, 361-366. (In Polish with English abstract.)

Parylak, K., Zięba, Z., Bułdys, A., Witek, K., 2013. Weryfikacja wyznaczania współczynnika filtracji gruntów niespoistych za pomocą wzorów empirycznych w ujęciu ich mikrostruktury. [The verification of determining a permeability coefficient of non-cohesive soil based on empirical formulas including its microstructure]. Acta Scientarum Polonorum Architectura, 12, 2, 43-51. (In Polish with English abstract.)

Pena, A. A., Garcia-Rojo, R., Herrmann, H. J., 2007. Influence of particle shape on shape dense granular media. Granular Matter, 9, 279-291.

Rasband, W.S., 1997-2016. ImageJ. U. S. National Institutes of Health, Bethesda, Maryland, USA, http://imagej.nih.gov/ij/. 
Santamarina, J.C., Cho, G.C., 2004. Soil behaviour: The role of particle shape. In: Proc. Skempton Conf. Advances in Geotechnical Engineering, Vol. 1, London, pp. 604-617.

Sasal, M.C., Andriulo, A., Taboada, M.A., 2006. Soil porosity characteristics and water movement under zero tillage in silty soils in Argentinian Pampas. Soil and Tillage Research, 87, 9-18.

Sheskin, D.J., 2003. Handbook of Parametric and Nonparametric Statistical Procedures. 3rd ed. Chapman \& Hall/CRC, Boca Raton, London, New York, Washington D.C., 1193 p.

Sinecen, M., Makinaci, M., Topal, A., 2011. Aggregate classification by using 3D image analysis technique. Gazi University Journal of Science, 24, 4, 773-780.

Thomas, M.C., Wiltshire, R.J., Williams, A.T., 1995. The use of Fourier descriptors in the classification of particle shape. Sedimentology, 42, 635-645.

Tiab, D., Donaldson, E.C., 2016. Porosity and permeability. In: Petrophysics. Theory and Practice of Measuring Reservoir Rock and Fluid Transport Properties. 4th ed. Elsevier, Amsterdam, pp. 67-186.

Tran, T.D., Cui, Y.J., Tang A. M., Audiguier, M., Cojean, R., 2014. Effects of lime treatment on the microstructure and hydraulic conductivity of Héricourt clay. Journal of Rock Mechanics and Geotechnical Engineering, 6, 399-404.

Utkaeva, V.F., 2007. Specific surface area and wetting heat of different soil types in European Russia. Eurasian Soil Science, 40, 11, 1193-1202.

Valentin, R., Sardini, P., Mazurier, A., Regnault, O., Descostes, M., 2016. Effective porosity measurements of poorly consolidated materials using non-destructive methods. Engineering Geology, 205, 24-29.

Vallejo, L., 1995. Fractal analysis of granular materials. Geotechnique, 45, 159-163.

Wadell, H., 1932. Volume, shape and roundness of rock particles. The Journal of Geology, 40, 443-451.

White, T.L., Williams, P.J., 1999. The influence of soil microstructure on hydraulic properties of hydrocarboncontaminated freezing ground. Polar Record, 35, 25-32.

Wolski, W., 1987. Filters, Report General. In: Proc. Int. IX European Conference on Soil Mechanics and Foundation Engineering, Vol. 3, Dublin, pp. 1351-1366.

Yagiz, S., 2001. Brief note on the influence of shape and percentage of gravel on the shear strength of sand and gravel mixtures. Bulletin of Engineering Geology and Environment, 60, 321-323.

\section{NOMENCLATURE}

$\zeta_{O C}(-) \quad$ total shape index

$\Phi(-) \quad$ sphericity

$A_{S}\left(\mathrm{~mm}^{2}\right)$ surface area of a sphere of the same volume as the particle

$A_{P}\left(\mathrm{~mm}^{2}\right)$ surface area of the particle

$A(-) \quad$ angularity

$\beta_{i}\left(^{\circ}\right) \quad$ angle bounding the particle edge

$x_{i}(\mathrm{~mm})$ distance from center of the maximum inscribed circle to the particle edges

$r(\mathrm{~mm}) \quad$ radius of the maximum inscribed circle, assumed to be the center of the particle

$I_{a}(-) \quad$ roughness

$P_{R}(\mathrm{~mm})$ actual perimeter of the particle

$P_{S}(\mathrm{~mm})$ simplified perimeter of the particle

$\zeta_{0}(-) \quad$ shape index

$\zeta_{\Phi}(-) \quad$ sphericity index

$\zeta_{1-A}(-) \quad$ angularity index

$\zeta_{\text {I-Ia }}(-) \quad$ roughness index

$\zeta_{\min }(-) \quad$ minimum shape index

$\zeta_{a v}(-) \quad$ average shape index

$\zeta_{\max }(-) \quad$ maximum shape index

$K\left(\mathrm{~m} \cdot \mathrm{s}^{-1}\right) \quad$ saturated hydraulic conductivity

$D_{p}(\mathrm{~mm})$ effective pore diameter according to the Pavchich model

$D_{p}{ }^{*}(\mathrm{~mm})$ effective pore diameter according to the modified Pavchich model

$n(-) \quad$ porosity

$I_{D}(-) \quad$ density index

$C_{u}(-) \quad$ uniformity coefficient

$C_{c}(-) \quad$ curvature coefficient

$S\left(\mathrm{~m}^{2} \cdot \mathrm{g}^{-1}\right)$ specific surface area

$D_{17}(-) \quad$ the size such that $17 \%$ of the particles are smaller than $\mathrm{D}_{17}$

$D_{i v}(\mathrm{~mm})$ effective pore diameter according to the Indraratna and Vafai model

$D_{i v}{ }^{*}(\mathrm{~mm})$ effective pore diameter according to the modified Indraratna and Vafai model

$\alpha(-) \quad$ shape factor

$D_{h}(\mathrm{~mm})$ mass weighted diameter

Received 16 October 2015 Accepted 25 July 2016 